\title{
Pharmacotherapy of Neuropathic Pain
}

\author{
Hindol Mondal ${ }^{1}$, Shouvik Choudhury ${ }^{2}$, Abhijit Das ${ }^{3}$, Anup K Bhattacharya ${ }^{4}$
}

\begin{abstract}
Neuropathic pain (NP), comprising a range of heterogeneous pathophysiological conditions, is often difficult to manage despite a number of treatment guidelines have been published worldwide. Most of the available treatments in these guidelines have moderate efficacy and present side effects that limit their use. Currently, there is a general agreement on appropriate first-line treatment of NP, whereas debate continues regarding second- and third-line treatments. First-line drugs include antidepressants (tricyclic antidepressants (TCAs) and serotonin-noradrenaline reuptake inhibitors (SNRIs)) and gabapentinoids. Second- and third-line drugs for NP include topical lidocaine, topical capsaicin, anticonvulsants, and opioids. A good understanding of pathophysiology of NP with the mechanism of action of currently available drugs along with their side effect profile helps to tailor therapies both to the specific neuropathic disease and to the needs of an individual patient. This review provides an overview of current drugs available for the treatment of NP with an emphasis on their mechanism of action.

Keywords: Capsaicin, Gabapentinoid, Neuropathic pain, Serotonin-noradrenaline reuptake inhibitor, Tricyclic antidepressant.

Bengal Physician Journal (2019): 10.5005/jp-journals-10070-6114
\end{abstract}

\section{INTRODUCTION}

According to the International Association for the Study of Pain (IASP), neuropathic pain (NP) is described as "pain caused by a lesion or disease of the somatosensory nervous system."1 It can be categorized as central or peripheral NP according to its origin. Peripheral NP originates from dysfunction or disease of the peripheral nerve, and conditions responsible for peripheral NP are diabetic neuropathy, postherpetic neuralgia, trigeminal neuralgia, radicular pain, postsurgical chronic NP, and neuropathic cancer pain. Central NP originates from a central lesion or diseases like stroke, spinal cord injury, and multiple sclerosis. ${ }^{2}$ Neuropathic pain is often underdiagnosed and prevalence of NP is difficult to estimate due to the lack of consensus on the definition of NP. In a systematic review of pain with neuropathic characteristics, we have found the incidence between $3 \%$ and $17 \% .{ }^{3}$ Though reports are scant on the prevalence in India, the burden is estimated to be enormous. In a recent evaluation from India, the reported prevalence of diabetic peripheral neuropathy (DPN) was $29.2 \%$ in patients with type 2 diabetes mellitus (T2DM). ${ }^{4}$

\section{Management of Neuropathic Pain}

Multiple international guidelines (Table 1) have suggested the following three classes of drugs as first-line agents: TCAs, SNRIs, and gabapentinoids. Rest of the drugs are considered as secondor third-line therapy and used in combination with first-line drugs when they are not effective alone or have low safety profile. ${ }^{5}$

\section{Antidepressants}

Tricyclic antidepressants and SNRIs were found to be effective in reducing NP. Amitriptyline is the most studied TCA and it did not show a dose-response effect. ${ }^{6}$ They have been shown to be effective in the treatment of peripheral neuropathy, postherpetic neuralgia, and NP post-spinal cord injury and of limited effect in radiculopathy, HIV, and chemotherapy-induced peripheral neuropathy. ${ }^{7}$ The usual starting dose for Indian population is as low as $10 \mathrm{mg}$, which should be titrated upward slowly to maximum of $50-75 \mathrm{mg}$ in divided doses. Tricyclic antidepressants act predominantly via inhibition of serotonin and noradrenaline reuptake; however, they also block
${ }^{1-3}$ Department of Pharmacology, Burdwan Medical College, Bardhaman, West Bengal, India

${ }^{4}$ Department of Medicine, Agartala Government Medical College, Agartala, Tripura, India

Corresponding Author: Shouvik Choudhury, Department of Pharmacology, Burdwan Medical College, Bardhaman, West Bengal, India, Phone: +91 9083806388, e-mail: shvk.choudhury@gmail.com

How to cite this article: Mondal H, Choudhury S, Das A, et al. Pharmacotherapy of Neuropathic Pain. Bengal Physician Journal 2019;6(2):28-30.

Source of support: Nil

Conflict of interest: None

histamine, adrenalin, acetylcholine, and sodium channels, resulting in a wide adverse effect profile. ${ }^{8}$

Among the SNRIs, duloxetine and venlafaxine are most commonly studied agents for NP. ${ }^{6,9}$ These drugs act by inhibiting noradrenaline and serotonin reuptake in nerve endings and thus increasing their concentration in the descending pain inhibition pathway. ${ }^{8}$ Duloxetine is very much effective in diabetic neuropathy and approved by Food and Drug Administration (FDA) for this purpose. Other painful peripheral neuropathy also responds well. ${ }^{10}$ In India, the standard dose of duloxetine starts with $20 \mathrm{mg}$ once daily at bedtime, which can be titrated up to $60 \mathrm{mg}$ in divided daily doses. Further higher dose can be given after considering the potential risk arising from different adverse effects and drug interactions. Venlafaxine is initiated at $37.5 \mathrm{mg}$ once at bedtime and can be increased cautiously up to maximum of $225 \mathrm{mg}^{11}$

\section{Gabapentinoids and Other Anticonvulsants}

Most commonly recommended drugs of this group are pregabalin and gabapentin, which are considered as the first-line therapy. ${ }^{5,12}$ They act by blocking the presynaptic a $2 \delta$ calcium channels in the dorsal horn in the central nervous system and the spinal cord and thus prevent neurotransmitter release. ${ }^{13}$ Both the agents are effective in diabetic neuropathy and postherpetic neuralgia. 
Table 1: Treatment recommendation from selected international organizations

\begin{tabular}{|c|c|c|c|c|}
\hline $\begin{array}{l}\text { Choice of } \\
\text { therapy }\end{array}$ & $\begin{array}{l}\text { Neuropathic Pain Special Interest } \\
\text { Group (NeupSIG) }(2015)^{5}\end{array}$ & $\begin{array}{l}\text { European Federation of Neuro- } \\
\text { logical Societies (EFNS) }(2010)^{22}\end{array}$ & $\begin{array}{l}\text { Canadian Pain Society } \\
(C P S)(2014)^{12}\end{array}$ & $\begin{array}{l}\text { National Institute for Care Excellence } \\
\text { (NICE) }\left(2013 \text {, updated 2017) }{ }^{23}\right.\end{array}$ \\
\hline First line & $\begin{array}{l}\text { Gabapentinoids: pregabalin, } \\
\text { gabapentin, gabapentin XRTCAs; } \\
\text { SNRIs: duloxetine, venlafaxine }\end{array}$ & $\begin{array}{l}\text { Gabapentinoids, SNRIs (DN); } \\
\text { TCAs, topicallidocaine (PHN) }\end{array}$ & $\begin{array}{l}\text { Gabapentinoids; TCAs; } \\
\text { SNRIs }\end{array}$ & $\begin{array}{l}\text { Gabapentinoids: pregabalin, } \\
\text { gabapentin; TCAs; SNRIs: fuloxetine }\end{array}$ \\
\hline Second line & $\begin{array}{l}\text { Capsaicin } 8 \% \text { patch; tramadol; } \\
\text { lidocaine patches }\end{array}$ & $\begin{array}{l}\text { Tramadol, strong opioids } \\
\text { (polyneuropathy); opioids, } \\
\text { capsaicin (PHN) }\end{array}$ & $\begin{array}{l}\text { Controlled release } \\
\text { opioids; tramadol }\end{array}$ & $\begin{array}{l}\text { Tramadol (short-term use for acute } \\
\text { rescue only) capsaicin cream }\end{array}$ \\
\hline Third line & Strong opioids botulinum toxin A & & Cannabinoids & \\
\hline
\end{tabular}

Flowchart 1: Treatment approach to neuropathic pain in Indian setup ${ }^{11}$

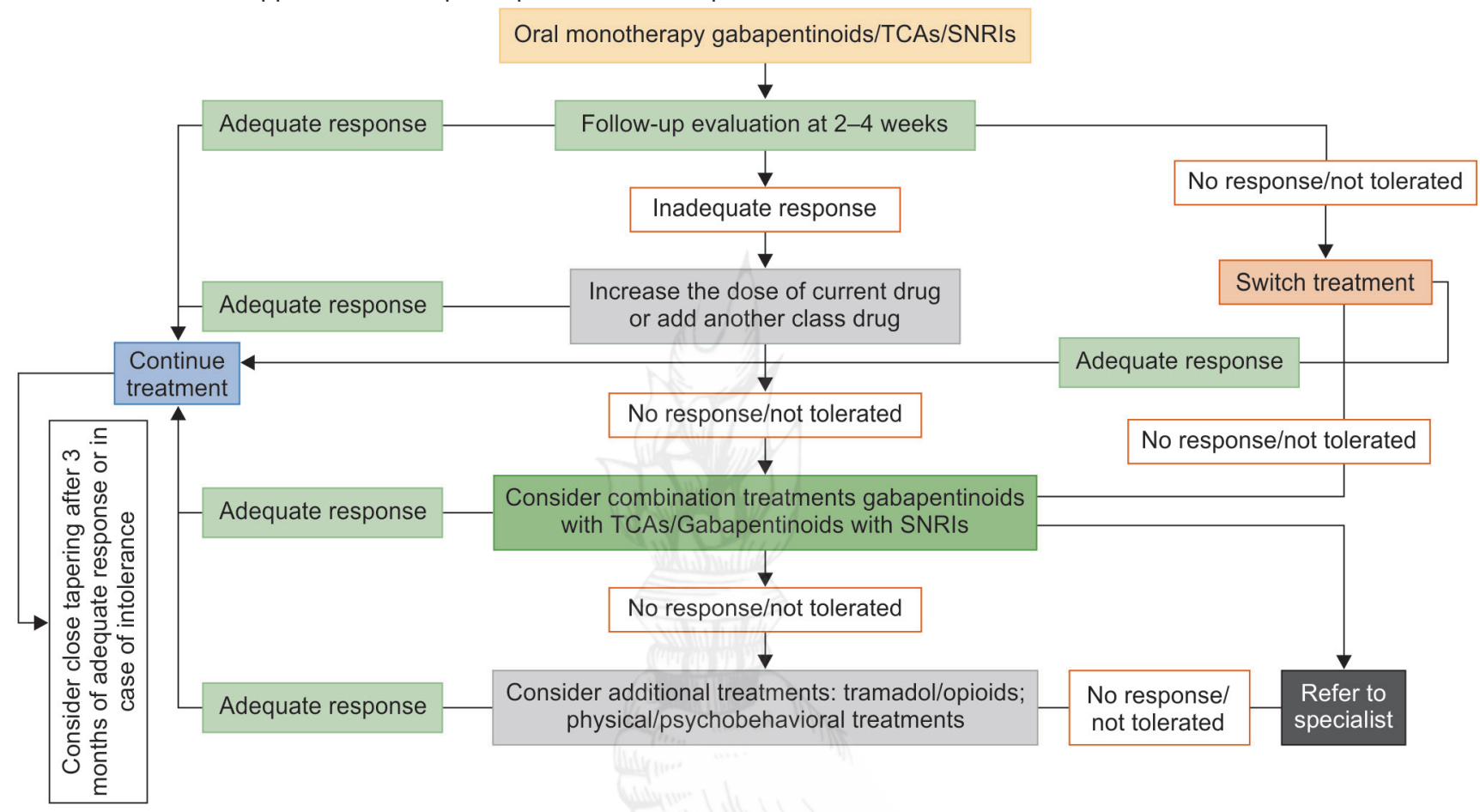

Pregabalin is already approved by US FDA in treatment of diabetic neuropathy. It is usually started with $50 \mathrm{mg}$ once at bedtime in the Indian scenario and can be gradually titrated up to maximum $450 \mathrm{mg}$ in two divided doses. Some patients may face dizziness, vertigo, and sedation as common adverse effects.

Gabapentin is initiated at $100 \mathrm{mg}$ once daily and carefully increased depending on efficacy and tolerability up to $1,800 \mathrm{mg}$ maximum daily in divided doses. ${ }^{11}$ Pregabalin and gabapentin are mostly excreted unchanged through the kidney, so depending on the renal function of the individual dose adjustment is required.

Other anticonvulsants such as carbamazepine, lamotrigine, topiramate, and sodium valproate are also considered useful in treatment of NP but due to lack of adequate evidences, these agents are not recommended to be used primarily. These agents are used by a specialist only in conditions where first-line drugs are not responding adequately. ${ }^{14}$

Neuropathic pain arising from trigeminal neuralgia shows superior response to carbamazepine and oxcarbazepine. Therefore, these agents are considered as standard therapy for this condition. It is currently recommended to test the HLA-B*1502 allele before prescribing these drugs to avert drug reactions with carbamazepine. $^{15}$

\section{Opioid Analgesics}

Opioid analgesics play an important role in alleviating NP. ${ }^{5}$ Interneurons present in the dorsal horn release endogenous opioids that work to reduce perceived pain. Endogenous substances (enkephalins, endorphins, and dynorphins) thus help in pain reduction and modulation by preventing transmission of pain signals to higher centers. Tramadol, a semisynthetic opioid agent, acts through multiple mechanisms of action but primarily acts as a weak $\mu$-opioid agonist and inhibitor of serotonin and norepinephrine reuptake. It is highly useful in acute NP, cancer-related NP, and intermittent exacerbations of NP. ${ }^{16,17}$ The initial dose is $25 \mathrm{mg}$ per day, which can be titrated gradually up to $100 \mathrm{mg}$ - three to four times daily depending on the safety and tolerability profile. Another newer opioid agent, tapentadol, is also used in NP but adequate evidence is unavailable. It acts little differently from tramadol by inhibiting noradrenaline reuptake strongly and has nearly no effect on serotonin reuptake. ${ }^{18}$

\section{Topical Agents}

Topical agents are recommended in some cases especially in elderly people as most of the oral medications are not tolerable to them and chances of adverse reactions increase. ${ }^{19}$ 
Topical lidocaine works by decreasing ectopic firing of peripheral nerves. It is beneficial in postherpetic neuralgia, postsurgical NP, and DPN. The $5 \%$ lidocaine patch is also available along with topical preparation. ${ }^{19,20}$

Capsaicin, another topical agent, acts through binding to the TRPV1 receptor located on the A $\delta$ and C-nerve fibers. This results in release of substance $P$ and depolarization of the nerve. The $8 \%$ capsaicin patch is advised in NP treatment. Though initial application is painful and irritating, which makes compliance poor, still regular use is helpful in reducing pain. ${ }^{19,21}$

\section{Emerging Therapies}

Multiple agents targeting novel mechanisms to control NP are currently under investigation, e.g., ketamine, memantine, bupropion, topical clonidine cannabinoids, ziconotide, etc. But international guidelines have recommended their strength as "inconclusive." Interventional modalities like local nerve blocks, spinal or epidural medicines, and neuroablative, neuromodulatory, neurosurgical procedures may also be useful in alleviating NP. ${ }^{5,14,15}$

There are no specific guidelines for management of NP in India and the therapy should be individualized according to the nature and cause of the pain as well as treatment tolerability and patient affordability. ${ }^{11}$ Focus should lie on controlling the primary disease like in diabetic neuropathy, strict glycemic control may reduce the neuropathy progression. Similarly, HIVassociated neuropathy treatment should consider antiretroviral treatment that itself can cause neuropathy on long-term use. Based on Indian setup, a treatment approach is given in Flowchart 1.

\section{Conclusion}

Our review demonstrated that even with evidence-based recommendations treatment of NP is challenging and only partial response is obtained with nearly all treatments. There is no standard treatment guideline in India for NP but side-by-side comparison of various international guidelines reveals that there is consistent recommendations on first- and second-line pharmacotherapies. The recommended treatments for general peripheral NP are amitriptyline, duloxetine, pregabalin, and gabapentin as first-line therapies. Opioids are generally used as rescue therapy and not recommended as first-line treatment due to safety issue and abuse potential on long-term use. Adverse effects related to many of these medications can also be very limiting in certain patient populations (e.g., TCAs in elderly patients); so, when using these medications patient's hepatic and renal function, age, and other comorbidities are kept into consideration. With pharmacotherapy patients with NP can expect a pain reduction, but the majority do not experience complete relief of pain.

\section{References}

1. Merskey H, Bogduk N. Task force on taxonomy of the International Association for the Study of Pain. Classification of Chronic Pain Descriptions of Chronic Pain Syndromes and Definitions of Pain Terms, 2nd ed., Seattle: IASP Press; 2002. p. 212.

2. Beniczky S, Tajti J, Timea VE, et al. Evidence-based pharmacological treatment of neuropathic pain syndromes. J Neural Transm (Vienna) 2005;112(6):735-749. DOI: 10.1007/s00702-005-0300-x.

3. Van Hecke O, Austin SK, Khan RA, et al. Neuropathic pain in the general population: a systematic review of epidemiological studies. Pain 2014;155(4):654-662. DOI: 10.1016/j.pain.2013. 11.013.

4. Bansal D, Gudala K, Muthyala $\mathrm{H}$, et al. Prevalence and risk factors of development of peripheral diabetic neuropathy in type 2 diabetes mellitus in a tertiary care setting. J Diabetes Investig 2014;5(6): 714-721. DOI: 10.1111/jdi.12223.

5. Finnerup NB, Attal N, Haroutounian S, et al. Pharmacotherapy for neuropathic pain in adults: a systematic review and meta-analysis. Lancet Neurol 2015;14(2):162-173. DOI: 10.1016/S1474-4422(14)70251-0.

6. Saarto T, Wiffen PJ. Antidepressants for neuropathic pain. Cochrane Database Syst Rev 2007;4:CD005454. DOI: 10.1002/14651858. CD005454.pub2.

7. Jensen TS, Madsen CS, Finnerup NB. Pharmacology and treatment of neuropathic pains. Curr Opin Neurol 2009;22(5):467-474. DOI: 10.1097/WCO.0b013e3283311e13.

8. Obata H. Analgesic mechanisms of antidepressants for pain. Int J Mol Sci 2017;18(11):E2483. DOI: 10.3390/ijms18112483.

9. Sindrup $\mathrm{SH}$, Otto $\mathrm{M}$, Finnerup NB, et al. Antidepressants in the treatment of neuropathicpain. Basic Clin Pharmacol Toxicol 2005;96(6):399-409. DOI: 10.1111/j.1742-7843.2005.pto_96696601.x.

10. Brown TR, Slee A. A randomized placebo controlled trial of duloxetine for central pain in multiple sclerosis. Int J MS Care 2015;17(2):83-89. DOI: 10.7224/1537-2073.2014-001.

11. Saxena AK, Jain P, Dureja GP, et al. Pharmacological management of neuropathic pain in India: a consensus statement from Indian experts. Indian J Pain 2018;32(3):132-144.

12. Mu A, Weinberg E, Moulin DE, et al. Pharmacologic management of chronic neuropathic pain: review of the Canadian Pain Society consensus statement. Can Fam Physician 2017;63(11):844-852.

13. Luo ZD, Chaplan SR, Higuera ES, et al. Upregulation of dorsal root ganglion (alpha)2(delta) calcium channel subunit and its correlation with allodynia in spinal nerve-injured rats. J Neurosci 2001;21(6): 1868-1875. DOI: 10.1523/JNEUROSCI.21-06-01868.2001.

14. Dworkin RH, O'Connor AB, Audette J, et al. Recommendations for the pharmacological management of neuropathic pain: an overview and literature update. Mayo Clin Proc 2010;85(3 Suppl):S3-S14. DOI: 10.4065/mcp.2009.0649.

15. Cruccu G, Gronseth G, Alksne J, et al. AAN-EFNS guidelines on trigeminal neuralgia management. Eur J Neurol 2008;15(10): 1013-1028. DOI: 10.1111/j.1468-1331.2008.02185.x.

16. Duehmke RM, Hollingshead J, Cornblath DR. Tramadol for neuropathic pain. Cochrane Database Syst Rev 2006;3:CD003726. DOI: 10.1002/14651858.CD003726.pub3.

17. Saxena AK, Nasare N, Jain S, et al. A randomized, prospective study of efficacy and safety of oral tramadol in the management of post-herpetic neuralgia in patients from North India. Pain Pract 2013;13(4):264-275. DOI: 10.1111/j.1533-2500.2012.00583.x.

18. Vadivelu N, Kai A, Maslin B, et al. Tapentadol extended release in the management of peripheral diabetic neuropathic pain. Ther Clin Risk Manag 2015;11:95-105. DOI: 10.2147/TCRM.S32193.

19. Casale R, Symeonidou Z, Bartolo M. Topical treatments for localized neuropathic pain. Curr Pain Headache Rep 2017;21(3):15. DOI: 10.1007/ s11916-017-0615-y.

20. Cheville AL, Sloan JA, Northfelt DW, et al. Use of a lidocaine patch in the management of postsurgical neuropathic pain in patients with cancer: a phase III double-blind crossover study (N01CB). Support Care Cancer 2009;17(4):451-460. DOI: 10.1007/s00520-0080542-x.

21. Derry S, Rice ASC, Cole P, et al. Topical capsaicin (high concentrations) for chronic neuropathic pain in adults. Cochrane Database Syst Rev 2017;1:CD007393. DOI: 10.1002/14651858.CD007393.pub4.

22. Attal N, Cruccu G, Baron R, et al. EFNS guidelines on the pharmacological treatment of neuropathic pain: 2010 revision. Eur J Neurol 2010;17(9):1113-e88. DOI: 10.1111/j.1468-1331.2010.02999.x.

23. National Institute of Health and Care Excellence (NICE) Clinical Guideline. Neuropathic Pain in Adults: pharmacological Management in Non-Specialist Settings; 2013. Available from: https://www.nice. org.uk/guidance/cg173. [Last updated on $2017 \mathrm{Feb}$ ]. 